\title{
EVALUATION OF RECENT GOCE GEOPOTENTIAL MODELS OVER THE AREA OF POLAND
}

\author{
Walyeldeen GODAH ${ }^{1,2)^{*}}$ and Jan KRYNSKI ${ }^{1)}$
}

\author{
1) Institute of Geodesy and Cartography, 27 Modzelewskiego St., 02-679 Warsaw, Poland \\ ${ }^{2)}$ University of Khartoum, AL-Jama'a St., 321-11115 Khartoum, Sudan \\ *Corresponding author's e-mail: w-hassan@igik.edu.pl
}

(Received January 2013, accepted March 2013)

\begin{abstract}
The dedicated satellite gravity missions have provided homogeneous and uniformly accurate information on the long and medium wavelengths of the Earth's gravity field. Since the launch of GOCE satellite gravimetry mission by the European Space Agency (ESA) in 2009, several global geopotential models (GGMs) have been published.

This study evaluates the recent GOCE-based GGMs over the area of Poland. The evaluation has been performed with the use of the EGM08 as well as high-precision GPS/levelling control traverse consisting of 184 stations. One GOCE-only GGM, four GOCE/GRACE satellite-only GGMs, and one GOCE/GRACE GGM combined with terrestrial gravity data have been selected for the evaluation. The results of inter-comparison of the models as well as their accuracy assessment have been discussed.
\end{abstract}

KEYWORDS: EGM08, geopotential model, GOCE, GPS/levelling, height anomaly, gravity anomaly

\section{INTRODUCTION}

The Gravity Field and Steady-state Ocean Circulation Explorer (GOCE) which is a core satellite mission of the European $\underline{\text { Space }}$ Agency (ESA) Living Planet Program (Drinkwater et al., 2003) was successfully launched on 17 March 2009 and started its operational measurements in September 2009. The objectives of the GOCE mission are to provide a highaccuracy, high-resolution global model of the Earth's static gravity field and the geoid, i.e. gravity anomalies of $1 \mathrm{mGal}$ accuracy and geoid of 1-2 cm accuracy, with spatial resolution of approximately $100 \mathrm{~km}$ or spherical harmonic expansion up to 200 degree and order $(\mathrm{d} / \mathrm{o})$. In order to achieve the mission objectives, GOCE satellite is equipped with a high-precision gravity gradiometer as well as a GPS receiver (ESA, 1999).

Since the launch of the GOCE mission, ESA has

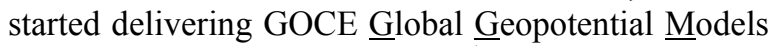
(GGMs) based on $\sim 2$ months ( $1^{\text {st }}$ release), $\sim 8$ months ( $2^{\text {nd }}$ release) and $\sim 12$ months ( $3^{\text {rd }}$ release) of effective data volume. Three different strategies are applied by ESA's GOCE High Level Processing Facility (HPF) for the determination of the Earth's gravity field. They are denoted as direct (DIR) solution, time-wise (TIM) solution and space-wise (SPW) solution (Rummel et al., 2004; Pail et al., 2011). In addition to ESA's solutions, combined models based on combination of GOCE data with the complementary gravity field from other satellite and terrestrial data, such as GOCO (Gravity Observation Combination) solution, EIGEN
(European Improved Gravity Models of the Earth by New Techniques) solution, and DGM (Delft Gravity Model) solution, were also developed by other institutions.

Several studies were performed by different research teams to assess the quality of GOCE-based GGMs in local gravity field modelling. They have been performed in different parts of the world using different processing procedure and different data sets, e.g. evaluations conducted by Ihde et al. (2010) in Germany, Janak and Pitonak (2011) in Central Europe, Hirt et al. (2011) worldwide, Šprlák et al. (2012) in Norway, Guimarães et al. (2012) in Brazil, etc.

In Poland, the $1^{\text {st }}, 2^{\text {nd }}$ and part of $3^{\text {rd }}$ release of GOCE GGMs were evaluated with the use of the EGM08 and high-precision GPS/levelling data (Godah and Krynski, 2012). The estimated standard deviations of the differences between the obtained from GOCE models and truncated EGM08 model height anomalies and gravity anomalies were within the range of 4-11 cm, and 1-3 mGal, respectively, and differences between height anomalies obtained from GOCE models and the corresponding ones at highprecision GPS/levelling control traverse sites were within the range of $8-11 \mathrm{~cm}$. The validation of GOCE-GGMs over Poland has shown their substantial improvement with the increasing period of GOCE observation used for the solutions. The main aim of this study is to pursue the evaluation of GOCE GGMs over Poland by including the recently developed 
Table 1 An overview information on GOCE GGMs evaluated.

\begin{tabular}{|c|c|c|c|c|c|c|}
\hline Model & DIR-R3 & TIM-R3 & GOCO- $03 \mathrm{~s}$ & DGM-1s & EIGEN-06s & EIGEN-06c \\
\hline Maximum d/o & 240 & 250 & 250 & 250 & 240 & 1420 \\
\hline Semi-major axis $a$ & 6378136.46 & 6378136.30 & 6378136.30 & 6378136.60 & 6378136.46 & 6378136.46 \\
\hline GOCE GPS-SST data & $\begin{array}{c}\mathrm{d} / \mathrm{o} 100 \\
12 \text { months }\end{array}$ & $\begin{array}{c}\mathrm{d} / \mathrm{o} 100 \\
12 \text { months }\end{array}$ & $\begin{array}{c}\mathrm{d} / \mathrm{o} 110 \\
12 \text { months }\end{array}$ & 14 months & - & - \\
\hline GOCE Gradiometry data & $\begin{array}{l}\mathrm{d} / \mathrm{o} 240 \\
12 \text { months }\end{array}$ & $\begin{array}{l}\mathrm{d} / \mathrm{o} 250 \\
12 \text { months }\end{array}$ & $\begin{array}{l}\mathrm{d} / \mathrm{o} 250 \\
12 \text { months }\end{array}$ & $\begin{array}{c}\mathrm{d} / \mathrm{o} 250 \\
10 \text { months }\end{array}$ & $\begin{array}{c}\mathrm{d} / \mathrm{o} 240 \\
6.7 \text { months }\end{array}$ & $\begin{array}{c}\mathrm{d} / \mathrm{o} 240 \\
6.7 \text { months }\end{array}$ \\
\hline $\begin{array}{l}\text { GRACE K-Band } \\
\text { Ranging }\end{array}$ & $\begin{array}{l}\mathrm{d} / \mathrm{o} 160 \\
7 \text { years }\end{array}$ & & $\begin{array}{l}\mathrm{d} / \mathrm{o} 180 \\
7.5 \text { years }\end{array}$ & 7 years & $\begin{array}{l}\mathrm{d} / \mathrm{o} 130 \\
6.5 \text { years }\end{array}$ & $\begin{array}{l}\mathrm{d} / \mathrm{o} 130 \\
6.5 \text { years }\end{array}$ \\
\hline GRACE GPS-SST data & $\begin{array}{l}\mathrm{d} / \mathrm{o} 160 \\
7 \text { years }\end{array}$ & - & $\begin{array}{l}\mathrm{d} / \mathrm{o} 180 \\
7.5 \text { years }\end{array}$ & $\begin{array}{l}\mathrm{d} / \mathrm{o} 180 \\
4 \text { years }\end{array}$ & $\begin{array}{l}\mathrm{d} / \mathrm{o} 130 \\
6.5 \text { years }\end{array}$ & $\begin{array}{l}\mathrm{d} / \mathrm{o} 130 \\
6.5 \text { years }\end{array}$ \\
\hline CHAMP GPS-SST data & - & & $\begin{array}{l}\mathrm{d} / \mathrm{o} 120 \\
5 \text { years }\end{array}$ & - & - & - \\
\hline LAGEOS-1/2 SLR data & $\begin{array}{l}\mathrm{d} / \mathrm{o} 3 \\
7 \text { years }\end{array}$ & - & $\begin{array}{l}\mathrm{d} / \mathrm{o} 5 \\
5 \text { years }\end{array}$ & - & $\begin{array}{l}\mathrm{d} / \mathrm{o} 30 \\
6.5 \text { years }\end{array}$ & $\begin{array}{l}\mathrm{d} / \mathrm{o} 30 \\
6.5 \text { years }\end{array}$ \\
\hline $\begin{array}{l}\text { Kaula regularization } \\
\text { constraints beyond } \mathrm{d} / \mathrm{o}\end{array}$ & 200 & 180 & 180 & 179 & - & H \\
\hline Terrestrial gravity data & - & - & - & - & - & $\begin{array}{l}\text { d/o } 1420 \\
\text { DTU10 }\end{array}$ \\
\hline Time of releasing & Nov 2011 & Nov 2011 & Jul 2012 & Sep 2012 & Jun 2011 & Jun 2011 \\
\hline
\end{tabular}
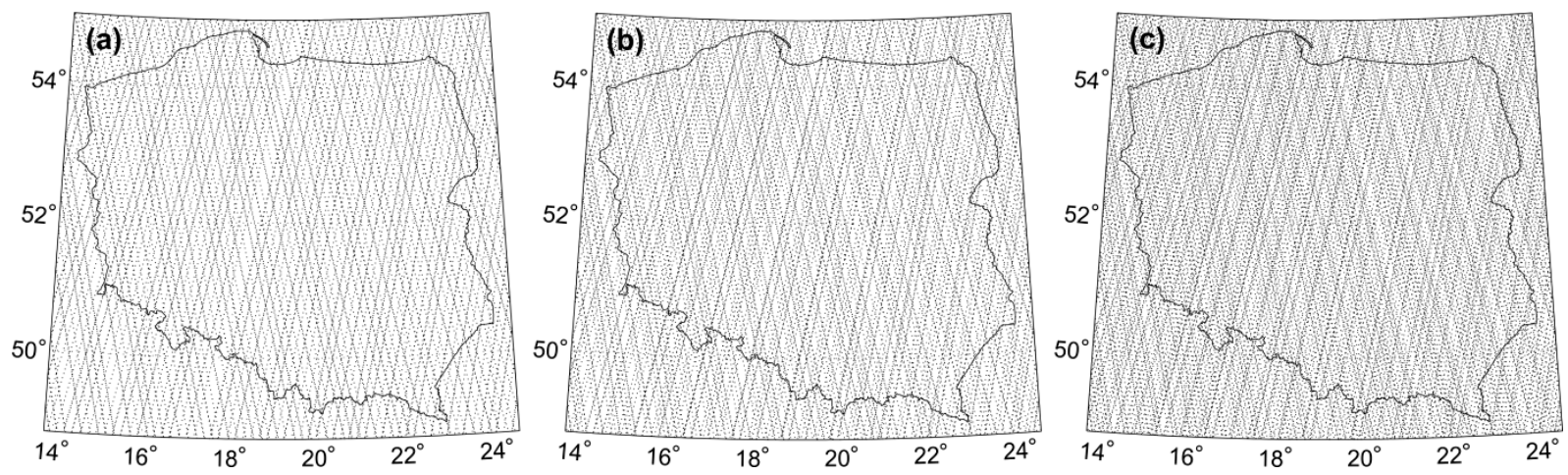

Fig. 1 GOCE satellite tracks over the evaluation area: period Nov 2009 - June 2010 (a), period Nov 2009 Dec 2010 (b), and period Nov 2009 - Apr 2011 (c) which correspond to effective data volume used in EIGEN-06 solution: 6.7 months (a), DGM-1s solution: $\sim 10$ months (b), and DIR-R3, TIM-R3 and GOCO-03s solutions: $\sim 12$ months (c).

GOCE GGMs as well as to evaluate the contribution of satellite gravity gradient data provided by GOCE mission to GGMs in spectral range from 100 to $\sim 250 \mathrm{~d} / \mathrm{o}$.

\section{GOCE GLOBAL GEOPOTENTIAL MODELS EVALUATED}

Six GOCE-based GGMs have been used in this study (Table 1). These models were released for public use via the International Centre for Global Earth Models (ICGEM) http://icgem.gfzpotsdam.de/ICGEM/ICGEM.html. The basic and most important information on these GGMs is provided on the header information of the GGMs files from ICGEM. It can be summarized as follows:

- The satellite-only DIR-R3, TIM-R3 and GOCO03s GGMs were developed with the use of approximately 12 months of GOCE $\underline{\text { Satellite }}$
Gravity Gradiometry (SGG) data (Fig. 1c). The TIM-R3 is a GOCE-only solution in a rigorous sense; no external gravity field information is used, neither as reference model, nor for constraining the solution (Pail et al., 2011). In the DIR-R3 (Bruinsma et al., 2010) and GOCO-03s solutions GRACE GPS-SST\&K-band range-rate data were used together with the GOCE data (Mayer-Gürr et al., 2012).

- The GFZ/GRGS satellite-only and combined gravity models EIGEN-06s and EIGEN-06c, were developed with the use of approximately 6.7 months of GOCE SGG data (Fig. 1b). EIGEN-06s is a satellite-based model up to $240 \mathrm{~d} / \mathrm{o}$, while EIGEN-06c is a combined high resolution model up to $1420 \mathrm{~d} / \mathrm{o}$ that contains terrestrial gravity data from DTU10 global gravity anomaly grid (Andersen, 2010). The first 

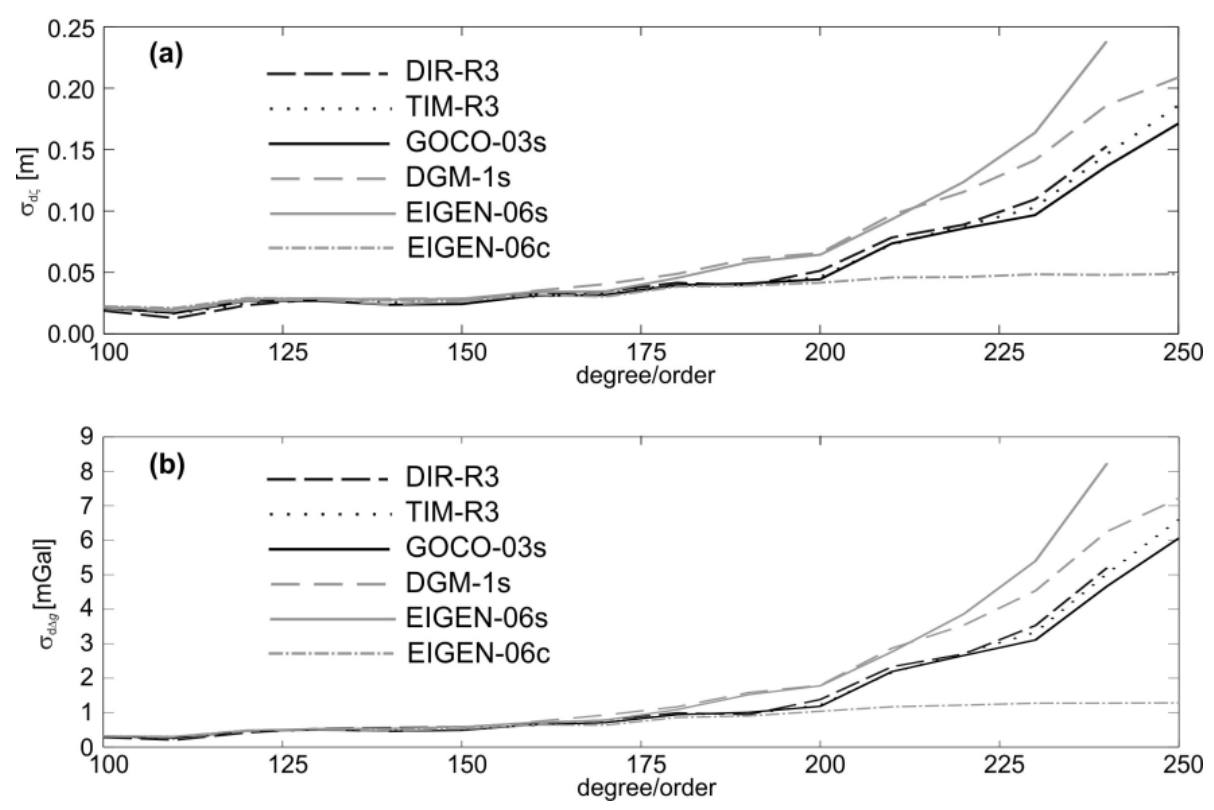

Fig. 2 Standard deviation of the differences between the EGM08 and GOCE-based GGMs in height anomalies (a), and gravity anomalies (b) $\left(N_{\max }=100,110\right.$, $120, \ldots, 250)$.

spherical harmonic coefficients $S H$ up to $50 \mathrm{~d} / \mathrm{o}$ are expressed as time variables in both models. The values of these coefficients can be determined at a certain epoch $(t)$ as follows (Förste et al., 2011):

$$
\begin{aligned}
S H(t)= & S H_{0}+T \cdot\left(t-t_{0}\right)+C 1 A \cdot \sin \left(\frac{2 \pi}{P_{1}}\left(t-t_{0}\right)\right)+ \\
& S 1 A \cdot \cos \left(\frac{2 \pi}{P_{1}}\left(t-t_{0}\right)\right)+C 2 A \cdot \sin \left(\frac{2 \pi}{P_{2}}\left(t-t_{0}\right)\right)+ \\
& S 2 A \cdot \cos \left(\frac{2 \pi}{P_{2}}\left(t-t_{0}\right)\right)
\end{aligned}
$$

where $T$ is the drift parameter, $S H_{0}$ is the spherical harmonic at the reference epoch $t_{0}=2005, C 1 A$, $S 1 A, C 2 A$ and $S 2 A$ are coefficients of periodic terms corresponding to two periods $P_{1}=1$ (annual) and $P_{2}=0.5$ (semi-annual) .

- The DGM-1s is a satellite-only GGM developed with the use of approximately 10 months' GOCE SGG data (Fig. 1a) in combination with the GRACE GPS-SST\&K-band range-rate data in optimal sense (Hashemi et al., 2012).

\section{NUMERICAL TESTS}

Two kinds of numerical tests were conducted to evaluate gravity anomalies and height anomalies from GOCE GGMs. First, GOCE-derived functionals were compared with the corresponding ones calculated from the EGM08 (Section 3.1). Secondly, they were compared with the ground truth height anomalies from the high-precision GPS/levelling control traverse (Fig. 3) (Section 3.2). For this purpose, gravity anomalies $\Delta g_{(r, \varphi, \lambda)}$ and height anomalies $\zeta_{(r, \varphi, \lambda)}$ were calculated using the following equations (Torge, 1991):

$$
\begin{aligned}
& \Delta g_{(r, \varphi, \lambda)}=\frac{G M}{a^{2}} \sum_{n=2}^{N_{\max }}(n-1)\left(\frac{a}{r}\right)^{n+2} \sum_{m=0}^{n} Y_{n m}(\varphi, \lambda) \\
& \zeta_{(r, \varphi, \lambda)}=\frac{G M}{a \gamma} \sum_{n=2}^{N_{\max }}\left(\frac{a}{r}\right)^{n+1} \sum_{m=0}^{n} Y_{n m}(\varphi, \lambda)
\end{aligned}
$$

with $Y_{n m}(\varphi, \lambda)$ - the spherical harmonic function given by

$$
Y_{n m}(\varphi, \lambda)=\left(C_{n m} \sin m \lambda+S_{n m} \cos m \lambda\right) \bar{P}_{n m}(\sin \varphi)
$$

where $G M$ is the geocentric gravitational constant, $a$ is the semi-major axis of the reference ellipsoid, $\bar{P}_{n m}(\sin \varphi)$ are fully normalized associated Legendre functions of degree $n$ and order $m,\left(C_{n m}, S_{n m}\right)$ are the Stokes' coefficients, $(r, \varphi, \lambda)$ are the geocentric coordinates of the computation point, $N_{\max }$ is the applied maximum degree of geopotential model, and $\gamma$ is the normal gravity on the reference ellipsoid at latitude $\varphi$.

\subsection{COMPARISONS OF GOCE GGMS WITH EGMO8}

The state-of-the-art combined global geopotential model EGM08 (Pavlis et al., 2012) has been used in this study as a reference model to evaluate the GOCE-based GGMs. This model was extensively evaluated over the area of Poland with the use of over 
Table 2 Differences between obtained from GOCE GGMs height anomalies and gravity anomalies and the corresponding ones calculated from the EGM08 $\left(N_{\max }=200\right)$.

\begin{tabular}{l|cccc|cccc}
\hline \multirow{2}{*}{\multicolumn{1}{c|}{ Model }} & \multicolumn{4}{|c|}{$\zeta_{\mathrm{GOCE}}-\zeta_{\mathrm{EGM} 08}[\mathrm{~m}]$} & \multicolumn{4}{c}{$\Delta g_{\mathrm{GOCE}}-\Delta g_{\text {EGM08 }}[\mathrm{mGal}]$} \\
\cline { 2 - 9 } & $\min$ & $\max$ & mean & std & $\min$ & $\max$ & mean & std \\
\hline DIR-R3 & -0.281 & -0.006 & -0.159 & 0.051 & -3.433 & 4.215 & 0.076 & 1.381 \\
TIM-R3 & -0.114 & 0.123 & 0.005 & 0.046 & -3.011 & 3.356 & 0.033 & 1.225 \\
GOCO-03S & -0.100 & 0.109 & 0.000 & 0.044 & -2.897 & 3.057 & -0.004 & 1.184 \\
DGM-1s & -0.441 & -0.111 & -0.300 & 0.066 & -3.836 & 5.143 & 0.036 & 1.794 \\
EIGEN-06s & -0.384 & 0.017 & -0.159 & 0.064 & -5.994 & 4.813 & 0.098 & 1.780 \\
EIGEN-06c & -0.299 & -0.034 & -0.162 & 0.042 & -3.504 & 3.212 & 0.017 & 1.041 \\
\hline
\end{tabular}

1000 height anomalies on GPS/levelling sites as well as regional precise quasigeoid models. Since the highquality gravity data from Poland were provided for developing the EGM08, the model has shown an excellent performance. The fit of the height anomalies $\zeta_{\text {EGM08 }}$ derived from the EGM08 to the corresponding ones $\zeta_{\mathrm{GPS} / \text { levelling }}$ obtained from GPS/levelling heights in Poland is almost as good as the height anomalies from best quasigeoid models available (Krynski and Kloch, 2009; Lyszkowicz, 2009).

Due to the new observable provided by the GOCE gradiometer instrument (Rummel, 2010) the significant contribution of GOCE to the development of GGMs is expected in the spectral range of 100 to $250 \mathrm{~d} / \mathrm{o}$. In this study, gravity anomalies and height anomalies were calculated over the area of Poland $\left(48^{\circ}<\right.$ latitude $<56^{\circ}, 13^{\circ}<$ longitude $\left.<24^{\circ}\right)$ using the GOCE GGMs and the EGM08 in the spectral range of 100 to $250 \mathrm{~d} / \mathrm{o}$ with $10 \mathrm{~d} / \mathrm{o}$ step, on the grid of $108^{\prime} \times 108^{\prime}$ to $43.2^{\prime} \times 43.2^{\prime}$, depending on the resolution of the model. The standard deviations $\sigma_{\mathrm{d} \zeta}$ and $\sigma_{\mathrm{d} \Delta g}$ of the differences between the GOCE GGMs and the EGM08 height anomalies and gravity anomalies, respectively, are shown in Figure 2. The statistics of those differences for the models truncated to $200 \mathrm{~d} / \mathrm{o}$ (100 km half wavelength) are presented in Table 2 .

All GOCE GGMs have provided quite similar results up to $\sim 175 \mathrm{~d} / \mathrm{o}$ (Fig. 2), which reflects the consistency of GOCE-only (as TIM-R3) solution and GOCE/GRACE solutions in this spectral range. Figure 2 shows also that adding more GOCE data has increased the accuracy of the GOCE GGMs solution beyond $175 \mathrm{~d} / \mathrm{o}$. From $200 \mathrm{~d} / \mathrm{o}$ onward the standard deviations have increased rapidly for all the GOCE GGMs solutions. This might be since the Stokes' coefficients are constrained with the use of Kaula's rule, however, adding more GOCE data have also enhanced the GOCE GGMs solutions. The EIGEN06c combined GGM generally gives better fit to the EGM08 beyond $200 \mathrm{~d} / \mathrm{o}$, which can be expected because of the terrestrial gravity data included in that model.

Standard deviations of differences shown in Table 2 are within the range of $4.2-6.6 \mathrm{~cm}$ for height anomalies, and 1.04-1.80 mGal for gravity anomalies. The means in Table 2 suggest that the bias values are obviously related to semi-major axis $a$ of reference ellipsoid which is not the same in the examined models (Table 1).

\subsection{COMPARISONS OF THE GOCE GGMS WITH THE GPS/LEVELLING DATA}

The traverse of $868 \mathrm{~km}$ crossing Poland from NE to SW (Fig. 3) was established in 2003-2004 for verification and accuracy estimation of quasigeoid models in Poland as well as for evaluation of the interpolation algorithms used for application of GPS/levelling quasigeoid models. The control traverse consists of 184 stations at the benchmarks of the vertical control; the accuracy of height anomalies at these sites is at the level of 1-2 cm (Krynski and Lyszkowicz, 2006).

The height anomalies $\zeta_{\mathrm{GOCE}}$ were calculated from the GOCE GGMs up to $200 \mathrm{~d} / \mathrm{o}$ at the GPS/levelling control traverse sites. To ensure the consistency of comparison, high frequency components (beyond

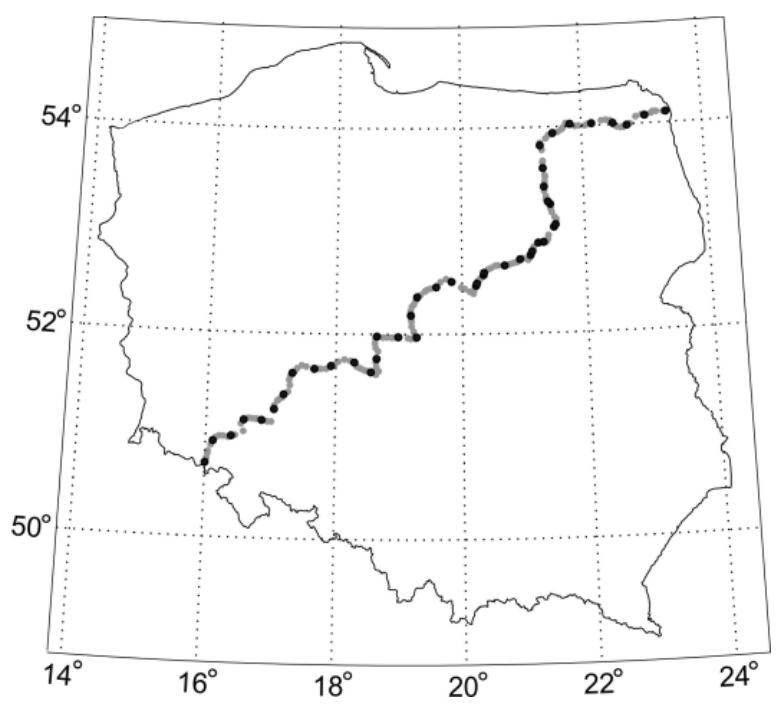

Fig. 3 The GPS/levelling control traverse crossing Poland form NE to SW; black dots $-1^{\text {st }}$ order (44 stations), grey dots $-2^{\text {nd }}$ order (140 stations). 

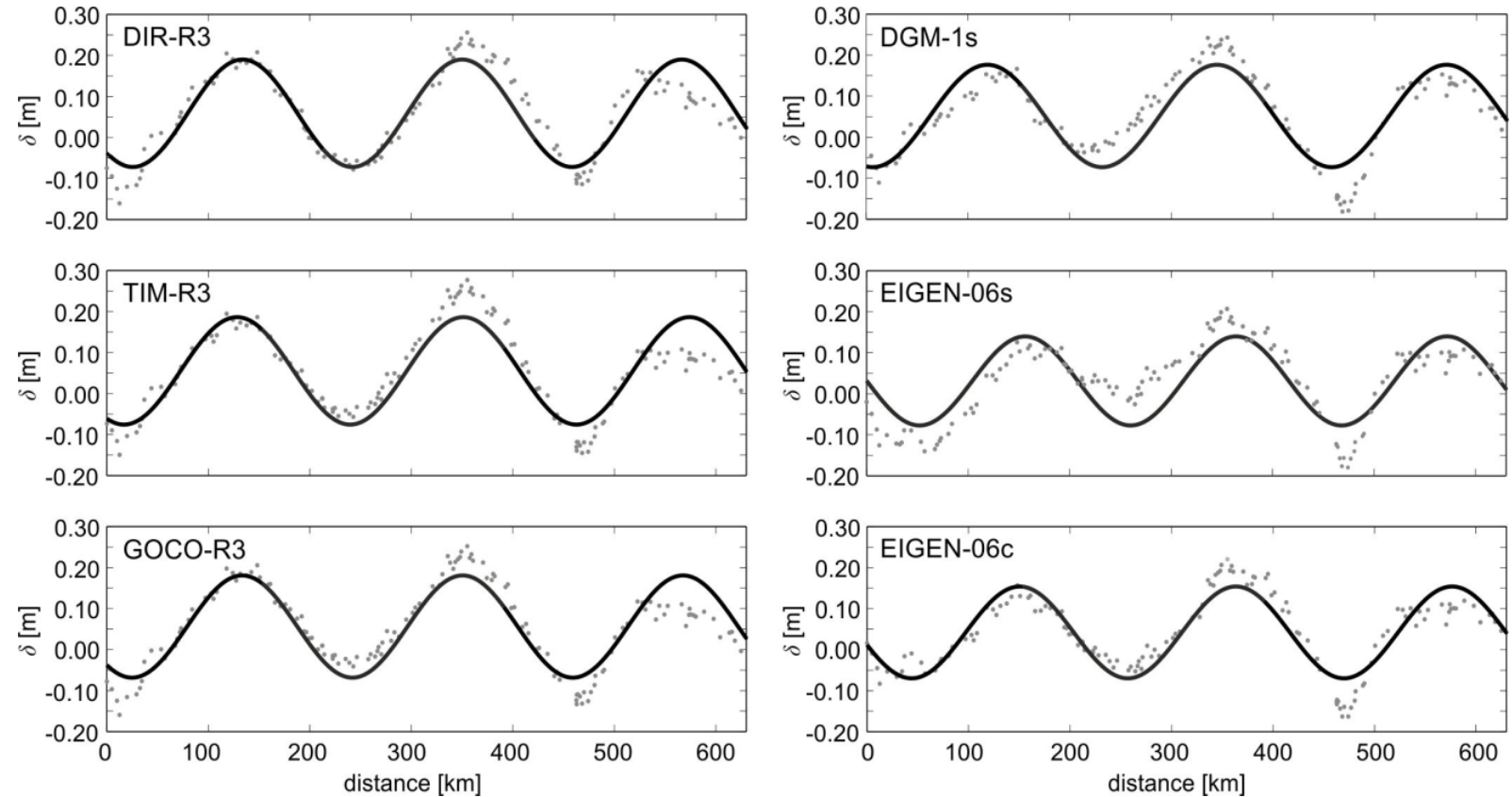

Fig. 4 Distribution of the differences $\delta$ between height anomalies from GOCE GGMs and the corresponding ones from the GPS/levelling control traverse showing the periodic pattern along the control traverse's chord.

Table 3 Statistics and estimated periodic pattern parameters of the differences $\delta$ between height anomalies obtained using GOCE GGMs $\left(N_{\max }=200\right)$ extended with EGM08 $\left(N_{\max }=201-2190\right)$ and the corresponding ones from the GPS/levelling control traverse.

\begin{tabular}{l|cccc|cccc}
\hline \multirow{2}{*}{ Model } & \multicolumn{4}{|c|}{ Statistics $[\mathrm{m}]$} & \multicolumn{3}{c}{ Estimated parameters of periodic pattern } \\
\cline { 2 - 9 } & min & $\max$ & mean & std & $B[\mathrm{~m}]$ & $A[\mathrm{~m}]$ & $\Phi[\mathrm{radian}]$ & $\lambda[\mathrm{km}]$ \\
\hline DIR-R3 & -0.161 & 0.256 & 0.057 & $\mathbf{0 . 1 0 5}$ & 0.05901 & -0.1310 & 0.8282 & $\mathbf{2 1 9}$ \\
TIM-R3 & -0.150 & 0.277 & 0.054 & $\mathbf{0 . 1 0 7}$ & 0.05525 & -0.1309 & 1.0960 & $\mathbf{2 2 6}$ \\
GOCO-03s & -0.159 & 0.252 & 0.055 & $\mathbf{0 . 1 0 1}$ & 0.05613 & -0.1246 & 0.8526 & $\mathbf{2 2 0}$ \\
DGM-1s & -0.181 & 0.243 & 0.052 & $\mathbf{0 . 1 0 2}$ & 0.05161 & -0.1248 & 1.3940 & $\mathbf{2 3 5}$ \\
EIGEN-06s & -0.180 & 0.207 & 0.030 & $\mathbf{0 . 0 9 6}$ & 0.03123 & -0.1085 & -0.0064 & $\mathbf{2 0 7}$ \\
EIGEN-06c & -0.163 & 0.220 & 0.041 & $\mathbf{0 . 0 9 1}$ & 0.04205 & -0.1119 & 0.2742 & $\mathbf{2 1 2}$ \\
\hline
\end{tabular}

$200 \mathrm{~d} / \mathrm{o}$ ) should be removed from height anomalies $\zeta_{\text {GPS/levelling }}$ of the GPS/levelling control traverse. They can be represented by omission error $\varepsilon_{o}$ from 201 to $2190 \mathrm{~d} / \mathrm{o}$, estimated from the EGM08 (Gruber, 2009)

$\varepsilon_{o}=\zeta_{\mathrm{EGM} 08} \begin{aligned} & N_{\max }=2190 \\ & N_{\max }=201\end{aligned}$

It should be emphasized that, the EGM08derived height anomalies exhibit standard deviation at the level of $\pm 2 \mathrm{~cm}$ at the GPS/levelling control traverse sites (Krynski and Kloch, 2009; Lyszkowicz, 2009), which almost satisfies the nowadays precision requirements of geoid/quasigeoid determination. However, the omission errors $\varepsilon_{o}$ at the GPS/leveling sites estimated using the EGM08 from 201 to 2190 $\mathrm{d} / \mathrm{o}$ were within the range from -33.0 to $+40.6 \mathrm{~cm}$. The differences $\delta$ between height anomalies $\zeta_{\mathrm{GOCB}}$ obtained from the GOCE GGMs and the corresponding ones $\zeta_{\text {GPS/levelling }}$ at GPS/levelling control traverse sites were thus obtained as follows:

$\delta=\left\{\zeta_{\mathrm{GPS} / \text { levelling }}-\varepsilon_{o}\right\}-\zeta_{\mathrm{GOCE}}$

Figure 4 shows the distribution of differences $\delta$ along the GPS/levelling control traverse. These differences display clearly a periodic pattern along the GPS/levelling control traverse chord. The parameters of this pattern were estimated with the use of the least squares method by approximating them with the sine function

$f(x)=B+A \cdot \sin \left(\frac{2 \pi}{\lambda} \cdot x+\Phi\right)$

where $B$ - bias, $A$ - amplitude, $\lambda$ - wavelength, and $\Phi$ - phase.

The periodic patterns of differences $\delta$ along the GPS/levelling control traverse have also been depicted in Figure 4. Statistics of those differences and the 


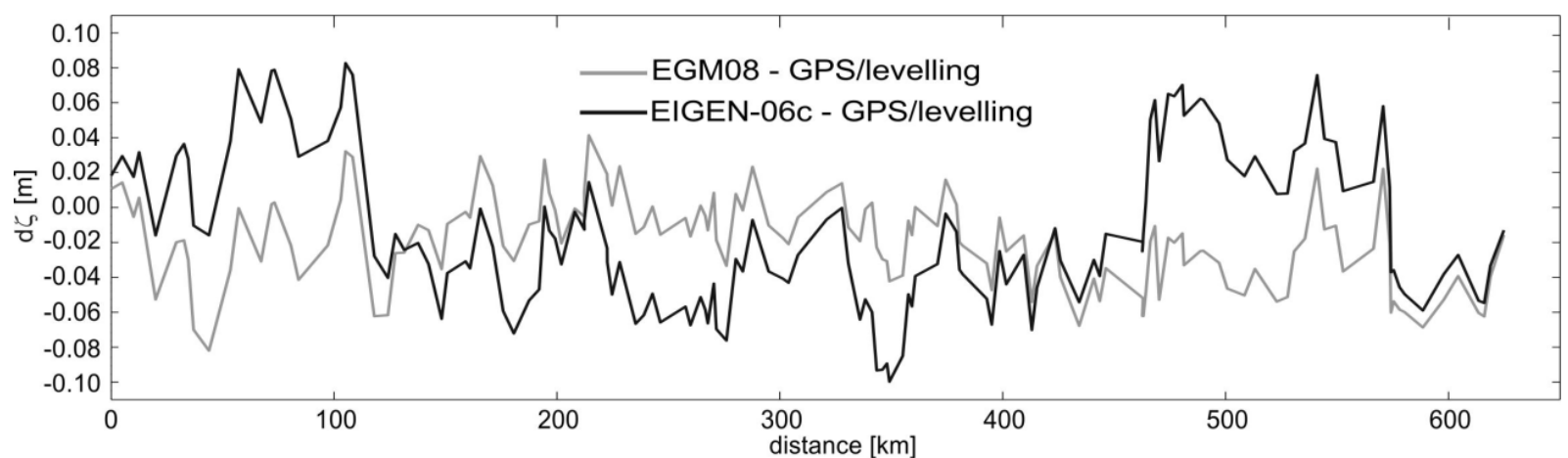

Fig. 5 Differences $d \zeta$ between height anomalies from EIGEN-06c and truncated EGM08 $\left(N_{\max }=1420\right)$, and the corresponding ones at GPS/levelling control traverse sites.
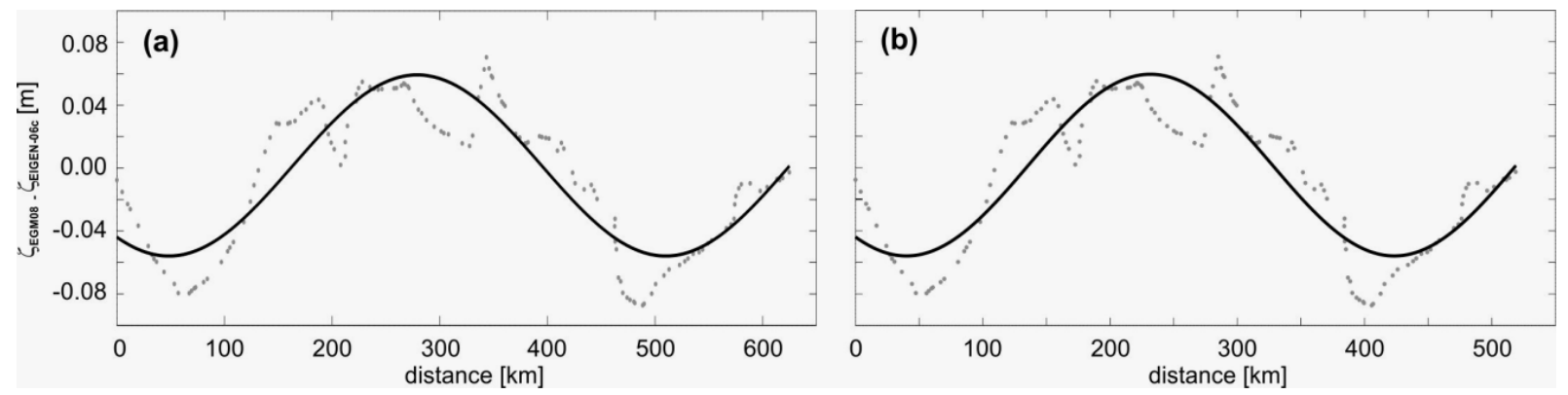

Fig. 6 Difference between height anomalies from EGM08 and EIGEN-06c at the GPS/levelling traverse sites $\left(N_{\max }=1420\right)$ along the GPS/levelling traverse chord (a) and along the parallel (b).

Table 4 Statistics of the differences $d \zeta$ between height anomalies derived using EGM08 and EIGEN-06c $\left(N_{\max }=1420\right)$ and the corresponding ones at GPS/levelling traverse sites $[\mathrm{m}]$.

\begin{tabular}{lcccc}
\hline $\begin{array}{l}\text { Model } \\
\left(N_{\max }=1420\right)\end{array}$ & Min & Max & Mean & Std \\
\hline EGM08 & -0.082 & 0.041 & -0.020 & 0.025 \\
EIGEN-06c & -0.100 & 0.083 & -0.013 & 0.045 \\
\hline
\end{tabular}

estimated parameters of the observed periodic pattern are given in Table 3.

In order to assess the accuracy of the EIGEN-06c against the EGM08, height anomalies $\zeta_{\text {EIGEN-06c }}$ have been calculated using all spherical coefficients of the EIGEN-06c model $\left(N_{\max }=1420\right)$ and likewise $\zeta_{\text {EGM08 }}$ using truncated EGM08 to $1420 \mathrm{~d} / \mathrm{o}$, at the GPS/levelling control traverse sites. Their differences $\mathrm{d} \zeta$ with respect to the height anomaly $\zeta_{\mathrm{GPS} / \text { levelling }}$ at the GPS/levelling control traverse sites are presented in Figure 5 and Table 4.

The differences between height anomalies obtained from EIGEN-06c model $\left(N_{\max }=1420\right)$ and truncated EGM08 to $1420 \mathrm{~d} / \mathrm{o}$ at the GPS/levelling control traverse sites exhibit also a periodic pattern along the GPS/levelling traverse chord as well as along the parallel after projecting the traverse distances onto the parallel (Fig. 6). One should not be surprised since the first spherical harmonic coefficients up to $50 \mathrm{~d} / \mathrm{o}$ of the EIGEN-06c were calculated with the use of sine/cosine function (cf. Eq. 1). The periodic pattern of that difference has been estimated using intuitive and simple model (Eq. 7).

The estimated wavelength values of the periodic pattern (Fig. 6) are $463 \mathrm{~km}$ and $385 \mathrm{~km}$ along the traverse chord and along the parallel, respectively. The latest one corresponds to the resolution of $50 \mathrm{~d} / \mathrm{o}$ of the GGM, which is considered as time variable part of EIGEN-06c solution while it is static (fixed values) in the EGM08.

\section{SUMMARY AND CONCLUSIONS}

The performance of the latest developed GOCE GGMs has been examined with use of the EGM08 and GPS/levelling control traverse data in Poland. The comparisons of corresponding height anomalies and gravity anomalies obtained from GOCE GGMs and from the EGM08 have revealed very good agreement for all GOCE GGMs solution up to $\sim 175 \mathrm{~d} / \mathrm{o}$. The comparisons also illustrate that, adding more GOCE data have improved the accuracy of the GOCE GGMs beyond $175 \mathrm{~d} / \mathrm{o}$.

For the models with $N_{\max }=200$ the deviation of the height anomalies and the gravity anomalies obtained using GOCE GGMs from the corresponding 
ones obtained using the EGM08 are at the level of $4.2-6.6 \mathrm{~cm}$ and $1.04-1.80 \mathrm{mGal}$, respectively. Among the satellite-only models, the GOCO-03s solution presents slightly best fit to the EGM08 solution.

For all GGMs investigated, except the EIGEN$06 \mathrm{c}$, from $N_{\max }=200$ onward, the noise contained in the GOCE observables dominates the signal in GGM solution. However, adding more GOCE data have successfully enhanced the GOCE GGMs solutions, which indicates that, in fact, with more GOCE data good solution can be obtained from the GOCE GGMs even below spatial resolution of $100 \mathrm{~km}(\sim 200 \mathrm{~d} / \mathrm{o})$.

Due to the terrestrial data included in the EIGEN-06c GGM the standard deviations of the height anomalies and the gravity anomalies are almost constant, exhibiting only very small increase when extending $N_{\max }$ beyond 200 .

The comparisons of the GOCE GGMs with the GPS/levelling control traverse data show that the accuracy of the height anomalies from the GOCE GGMs in terms of their standard deviation at $N_{\max }=$ 200 is at the level of $10 \mathrm{~cm}$. The differences obtained show a periodic pattern along the GPS/levelling control traverse chord. The estimated wavelengths of this pattern are within the range of $212-235 \mathrm{~km}$. Moreover, the fit of height anomalies obtained from the high resolution EIGEN-06c combined GGM and truncated EGM08 $\left(N_{\max }=1420\right)$ at the GPS/levelling control traverse sites is of $4.2 \mathrm{~cm}$ and $2.5 \mathrm{~cm}$, respectively. Furthermore, the distribution of differences between height anomalies from EIGEN06c and EGM08 $\left(N_{\max }=1420\right)$ at the GPS/levelling control traverse sites, show also a distinctive periodic pattern of $463 \mathrm{~km}$ and $385 \mathrm{~km}$ periods along the traverse chord and along the parallel, respectively. This pattern can be interpreted as the impact of the long wavelength bias between the EIGEN-06c and EGM08 solutions.

The analyses performed demonstrate the potentiality of using high-precision and highresolution GPS/levelling control traverse for the evaluation of the GGMs. The availability of such GPS/levelling control traverse data across the country offers a unique possibility for further studies on the evaluation of the GGMs based on satellite data.

\section{ACKNOWLEDGMENTS}

The research was done in the framework of the statutory project "Problems of geodesy and geodynamics" of the Institute of Geodesy and Cartography, Warsaw, financially supported by the Polish Ministry of Science and Higher Education.

\section{REFERENCES}

Andersen, B.: 2010, The DTU10 Gravity field and mean sea surface -improvements in the Arctic, $2^{\text {nd }}$ International Symposium of the Gravity Field of the Earth (IGFS2), Fairbanks, Alaska, 20-22 September 2010.

Bruinsma, S.L., Marty, J.C., Balmino, G., Biancale, R., Foerste, C., Abrikosov, O. and Neumayer, H.: 2010, GOCE Gravity field recovery by means of the direct numerical method, Proceedings of the ESA Living Planet Symposium, 28 June - 2 July 2010, Bergen, Norway, see also: earth.esa.int/GOCE.

Drinkwater, M., Floberghagen, R., Haagmans, R., Muzi, D. and Popescu, A.: 2003, GOCE: ESA's first Earth explorer core mission, Space Science Reviews, 18, No. 1-2, 419-432. DOI: 10.1023/A:1026104216284

ESA: 1999, Gravity Field and Steady-State Ocean Circulation Mission, Report for mission selection of the four candidate Earth Explorer missions, ESA SP 1233(1).

Förste, C., Bruinsma, S., Shako, R., Marty, J.-C., Flechtner, F., Abrykosov, O., Dahle, C., Lemoine, J.-M., Neumayer, K.-H. and Biancale, R.: 2011, EIGEN-6 A new combined global gravity field model including GOCE data from the collaboration of GFZ Potsdam and GRGS Toulouse, EGU General Assembly, Vienna, Austria, 2011.

Godah, W. and Krynski, J.: 2012, Validation of GOCE geopotential models over Poland using the EGM2008 and GPS/levelling data, Geoinformation Issues, 3, No. 1, 5-17.

Gruber, T.: 2009, Evaluation of the EGM2008 gravity field by means of GPS-Leveling and sea surface topography solutions, Special Issue: In External quality evaluation reports of EGM2008, Newton's Bulletin, 4, 3-17.

Guimarães, G., Matos, A. and Blitzkow, D.: 2012, An evaluation of recent GOCE geopotential models in Brazil, Journal of Geodetic Science, 2, No. 2, 144 155. DOI: $10.2478 / \mathrm{v} 10156-011-0033-8$

Hashemi Farahani, H., Ditmar, P., Klees, R., Liu X., Zhao, Q. and Guo, J.: 2012, The Earth's static gravity field model DGM-1S from an optimal combination of GRACE and GOCE data: computation and validation aspects, Journal of Geodesy, in review.

Hirt, C., Gruber, T. and Featherstone, W.E.: 2011, Evaluation of the first GOCE static gravity field models using terrestrial gravity, vertical deflections and EGM2008 quasigeoid heights, Journal of Geodesy, 85, No. 10, 723-740. DOI: $10.1007 / \mathrm{s} 00190-011-0482-\mathrm{y}$

Ihde, J., Wilmes, H., Müller, J., Denker, H., Voigt, C. and Hosse, M.: 2010, Validation of satellite gravity field models by regional terrestrial data sets, System Earth via Geodetic-Geophysical Space Techniques, Advanced Technologies in Earth Sciences, Part 3, 277-296. DOI: 10.1007/978-3-642-10228-8_22

Janák, J. and Pitoňák, M.: 2011, Comparison and testing of GOCE global gravity models in Central Europe, Journal of Geodetic Science, 1, No 4, 333-347. DOI: $10.2478 / \mathrm{v} 10156-011-0010-2$

Krynski, J. and Kloch, G.: 2009, Evaluation of the performance of the new EGM08 global geopotential model over Poland, Geoinformation Issues, 1, No. 1, $7-17$.

Krynski, J. and Lyszkowicz, A.: 2006, The overview of precise quasigeoid modelling in Poland, Contributions to Geophysics and Geodesy, Special issue, WIGFR 2006, Geophysical Institute of Slovak Academy of Sciences, 113-149.

Lyszkowicz, A.: 2009, Assessment of accuracy of EGM08 model over the area of Poland, Technical Sciences 12, UWM Olsztyn. DOI: 10.2478/v10022-009-0011-x

Mayer-Güerr, T., Rieser, D., Höck, E., Brockmann, J.M., Schuh, W.-D., Krasbutter, I., Kusche, J., Maier, A., Krauss, S., Hausleitner, W., Baur, O., Jäggi, A., Meyer, U., Prange, L., Pail, R., Fecher, T. and Gruber, 
T.: 2012, The new combined satellite only model GOCO03s, GGHS 2012, Venice, 8-12 October 2012.

Pail, R., Bruinsma, S., Migliaccio, F., Förste, C., Goiginger, H., Schuh, W., Höck, E., Reguzzoni, M., Brockmann, J., Abrikosov, O., Veicherts, M., Fecher, T., Mayrhofer, R., Krasbutter, I., Sansò, F. and Tscherning, C.C.: 2011, First GOCE gravity field models derived by three different approaches, Journal of Geodesy, 85, No. 11, 819-843.

DOI: $10.1007 / \mathrm{s} 00190-011-0467-\mathrm{x}$

Pavlis, N.K., Holmes, S.A., Kenyon, S.C. and Factor, J.K.: 2012, The development and evaluation of the Earth gravitational model 2008 (EGM2008), J. Geophys. Res., 117, 804406. DOI: 10.1029/2011JB008916

Rummel, R.: 2010, GOCE: Gravitational Radiometry in a Satellite, in: W. Freeden, M.Z. Nashed, T. Sonar (eds), Handbook of Geomathematics, 2, 93-103, Springer, ISBN (Print) 978-3-642-01545-8, ISBN (Online) 978-3-642-01546-5.

DOI: $10.1007 / 978-3-642-01546-54$

Rummel, R., Gruber, T. and Koop, R.: 2004, High level processing facility for GOCE: products and processing strategy, Proc. $2^{\text {nd }}$ International GOCE User Workshop "GOCE, The Geoid and Oceanography", Frascati, Italy, 8-10 March 2004, ESA SP-569.

Šprlák, M., Gerlach, C. and Pettersen, B.: 2012, Validation of GOCE global gravity field models using terrestrial gravity data in Norway, Journal of Geodetic Science, 2, No. 2, 134-143. DOI: 10.2478/v10156-011-0030-y

Torge, W.: 1991, Geodesy, 2nd edition, Walter de Gruyter, Berlin-New York. 